\title{
Courtship Initiation Behaviour in Online Personals
}

\author{
Kesumawati A. Bakar ${ }^{1}$ \\ ${ }^{1}$ School of Language Studies and Linguistics, Universiti Kebangsaan Malaysia, Bangi, Selangor, Malaysia \\ Correspondence: Kesumawati A. Bakar, School of Language Studies and Linguistics, Universiti Kebangsaan \\ Malaysia, Bangi, 43600, Selangor, Malaysia. Tel: 60-12-775-5673. E-mail: kesuma@ukm.edu.my
}

Received: April 12, 2016 Accepted: April 21, 2016 Online Published: June 21, 2016

doi:10.5539/ass.v12n7p17 URL: http://dx.doi.org/10.5539/ass.v12n7p17

\begin{abstract}
A personal advertisement has two aims; to promote its author and to attract potential love interest. In addition to providing textual information about physical appearance, occupation and interests, accompanying images in personal ads create meanings that are instrumental in building imaginary relations between the advertiser and the readers. This paper explores the notions of body language and interpersonal attitude and courtship initiation behaviour in online personal ads. Using Kress \& van Leeuwen's Grammar of Visual Design (2006) and Mehrabian's dominant and affiliative dimensions (1981) this study examines how interpersonal relations are represented through the embodiment of affiliative and non-affiliative attitudes in images. Analysis of 581 images reveals several common visual personas through specific clusters of bodily stance and facial articulation that are instrumental in creating and establishing represented affiliation between the participants in the images and the viewers. As such this study is a contribution to scholars working in the area of visual analysis, identity and social semiotics as it identifies non-verbal realizations of affiliative and non-affiliative attitudes and demonstrates their interaction through a corpus-based analysis of personal ad images.
\end{abstract}

Keywords: body language, social semiotics, interpersonal attitude, affiliative-non-affiliative, dominant-submissive

\section{Introduction}

A personal advertisement constitutes a distinct generic form, which is related to the small ad family of genres. While small ads traditionally offer a thing (e.g. a car) or a service (e.g. plumbing), the personal ad 'offers but, most essentially, seeks' (Shalom, 1997) a romantic partner. Accordingly, a personal ad is used for the purpose of 'selling' oneself and of 'seeking' a desired other for short and long term relationships (Shalom, 1997; Marley, 2000; Gibbs et al., 2006). Each construed identity in a personal ad is an offer that is intended to be exchanged for what is sought by others in the dating scene. The self becomes a commodified entity and advertisers compete for the time and effort of other members to read and respond to their profiles. With these aims in mind, advertisers are pushed into crafting an advert that will positively highlight their identity in ways that they believe will help them achieve these objectives.

Virtual dating site creates courting potentiality that begins online and then moves on to offline face-to-face interactions, forming what is termed as a mixed-mode relationship (Walther \& Parks, 2002). An interesting myth about online daters is that they are social isolates in the real world (Fiore, 2004). There may have been some truth to this perception when online dating was in its infancy (Klement, 1997). However a survey among Canadian online daters at the end of 2000 revealed little evidence to support this generalization. The results of the survey revealed that online daters are sociable individuals who tend to be members of social networks, are family-oriented and frequently engage in social and leisure activities with others (Brym \& Lenton, 2001). Partly due to the above stigma, self-advertisement in Malaysia was initially perceived as an unconventional way of meeting people and was therefore a less popular method than the traditional approach of formal face-to-face meetings. However, the recent creation of reality matchmaking shows on Malaysian television channels and an increasing number of local online dating and marital sites have demonstrated a change in attitude towards this alternative mode of meeting people. A survey recently revealed that $46 \%$ of Malaysian Internet users visit social networking sites, which include some matchmaking sites (The Star, 2007). Additionally, a search for "Malaysian online dating sites" on Google revealed 23,800 results. Based on the growing number of users and dating programs and sites in the media and on the Internet, the phenomena of online dating has established its position as a new social practice in the act of courtship initiation. 
The increasing popularity of personal ads among relationship-seeking adults has triggered studies in fields ranging from social sciences to humanities to computer sciences. Findings have developed insights into various issues pertaining to social and cultural practices, ranging from language to gender to power relations in society. Social science researchers have for example been using personal ads to study what people are willing to disclose about themselves and what they are seeking in others for over thirty years. Some of the earliest findings of these studies (e.g. Cameron et al., 1977) have showed that people tend to make requests that are congruent with their sex-role stereotypes. For instance, women are more likely to express interest in financial security, sensitivity, and sense of humour of a prospective partner, while men are more likely to seek an attractive partner with whom they can have a sexual relationship. In cases where personal ads are used to measure the supposed desirability of certain attributes, findings have generally revealed that physical characteristics are generally more important than personality characteristics for men than women (e.g. Hogben \& Coupland, 2000; Miller et al., 2000; Bartholome et al., 2007).

While the written text presents the main means for representing the advertiser's identity, several researchers have discussed the benefits of attaching photos in online profiles (Walther, 2001; Fiore, 2002). Findings demonstrated that profiles with photos attracted a higher number of responses than those without. One significant factor here is the fact that physical attractiveness appears to be one of the most important characteristics men seek in their prospective partner (Bolig et al., 1984; Shalom, 1998). Accordingly, images function to validate the attractiveness of the advertisers (Jones, 2009, p. 117). Apart from functioning as one of the tools by which advertisers engender interest, images also reveal physiological (e.g. body type and facial features) and social information (e.g. occupation and interests) about the advertiser and thus are, to a certain extent, a manifestation of the written description.

Accordingly, images in personal ads are multi-functional in nature (Jones, 2009). 'They are aesthetic resources that reveal individuals' characters, histories and particular physical traits. Their most important function, however, is to attract the attention of the viewers' (Jones, 2009, p. 120). This paper specifically focuses on how images in personal ads function as a tool for for affiliating with others; more specifically, the ways in which the advertisers enact imaginary relationships with the viewers through their body language. Inspired by Kress and van Leeuwen's grammar of visual design $(1996,2006)$, this paper identifies and describes body language in terms of its realization through features of posture, facial expression, social distance and angle and the way in which each feature realizes interpersonal meaning. The aim here is to systematically describe and codify interpersonal visual resources in personal ad images. These features form the basis for the systematic coding of body language in the advertisers' images using the UAM corpus tool program (O'Donnel, 2008). Additionally, the ways in which these visual resources are captured in the images also draw on the dimensions of framing (i.e. the type of shot) and perspective (i.e. side or front angle). The following example in Figure 1.0 highlight the visual interpersonal resources deployed by the advertiser.

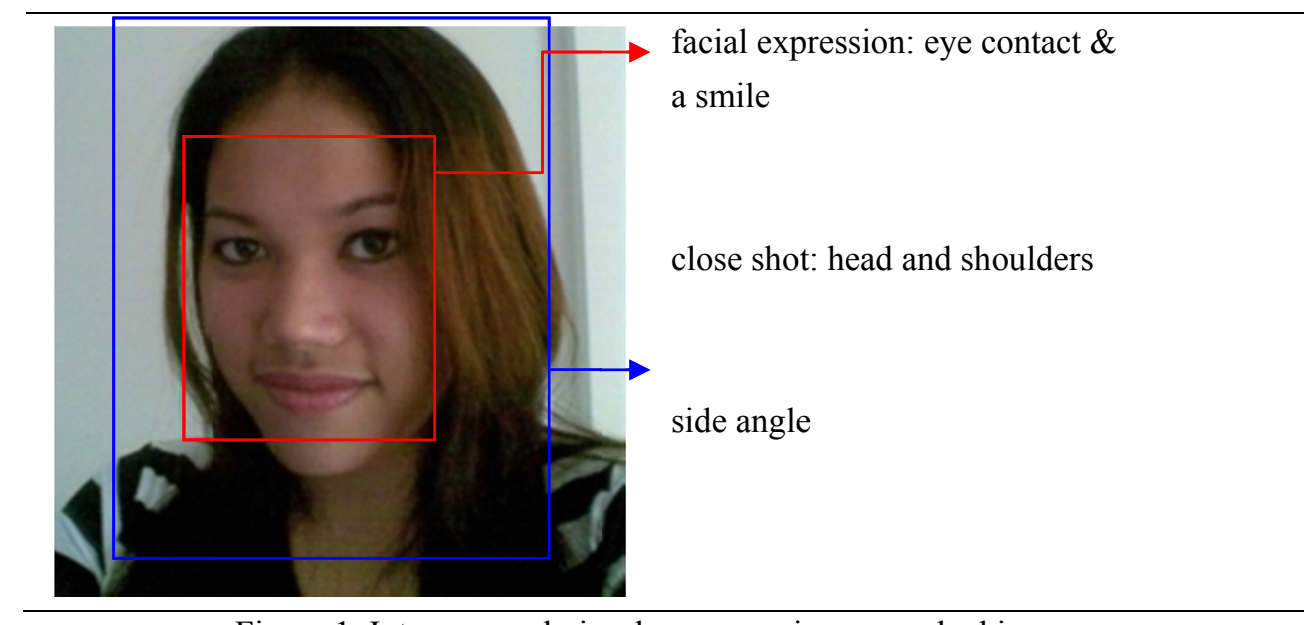

Figure 1. Interpersonal visual resources in personal ad images

Ultimately, different types of visual personae will be generalized based on the clustering of body language features, framing and perspective. The framework for visual analysis integrates features from social semiotic work on visual grammar (Kress \& van Leeuwen, 1996, 2006) and facial affect (Painter \& Martin, 2010; Tian, 
2010), and also body posture, drawing on work in social behavioural science by Mehrabian $(1971,1981)$ and Argyle (1988).

Based on the framework of social semiotics, social behavioural science and corpus linguistics techniques, this paper specifically addresses the following questions.

1. What are the dominant patterns of non-verbal features displayed by the men and women in their personal ad images?

2. What are the types of interpersonal attitude represented through the advertisers' body language and the resources they use to affiliate with viewers on Match.com?

3. To what extent are the realizations of face-to-face courtship initiation behavior represented in the advertisers' images?

The following sections will describe the concept and features of body language in the fields of social semiotics and social behavioural science.

\subsection{Body Language in Behavioural Science}

Research on non-verbal communication in social behavioral science goes at least as far back as Darwin's 'The Expression of the Emotion in Man and Animals' in 1872 which focused on his observation of facial expressions and body language from an evolutionary perspective (Ekman, 1992). At its most basic, the phrase "nonverbal communication" (henceforth NVC) is identified with message sources that are not a part of written and spoken language (Knapp et al., 1978). Generally, NVC is used to refer to "all of the ways in which communication is effected between persons when in each other's presence, by means other than words. It refers to the communicational functioning of bodily activity, gesture, facial expression and orientation, posture and spacing, touch and smell, and of those aspects of utterance that can be considered apart from the referential content of what is said" (Kendon, 1981, p. 3).

The first part of my image analysis focuses on the resources that are used by the advertisers to enact interpersonal relationship with the viewers. The aim here is to systematically describe and codify visual interpersonal resources in personal ad images. These resources are somatic in nature as they involve features of body language such as facial expression and posture. Argyle (1988) provided a list of features that are categorised as non-verbal communication based on the findings of previous scholars. These are facial expression, gaze, gestures, posture, bodily contact and other aspects of appearance and non-verbal vocalizations. Each of these can be subdivided into a number of variables or discrete choices. For example, Argyle (1988) distinguished between three main human postures: 1) sitting, squatting and kneeling; 2) standing and 3) lying. He explains that each of these has variations corresponding to different positions of the arms and legs and different angles of the body. He proposed a number of terms that are commonly adopted in describing postures which are used to encode the advertisers' bodily stances in this study:

1. lean - forward; backward; sideways

2. arms - open; closed; on hips

3. head - lowered; raised; tilted sideways

4. legs - stretched; open; crossed

Additionally, the ways in which these non-verbal resources are captured in the images also draw on the dimensions of framing (i.e. the type of shot) and perspective (i.e. side or front angle)

\subsection{Body Language and Systemic Functional Grammar}

Systemic functional scholars have generally drawn on the grammatics of systemic functional linguistics to analyze and systematize non-verbal language into modes of meaning and expression, motivated by the metafunctions. System networks have been adapted as one way of representing meaning making choices in bodily and facial expressions, in real-time interaction or static representation in images (e.g. Kress \& van Leeuwen, 1996; 2006; Martinec, 2001, 2004; Hood, 2011; Painter \& Martin, 2009). Through a system network, body language is modeled as sets of alternatives or 'systems' of meaning choices with specific realizations (see section 2.3.4), akin to the one provided for language by Halliday (1966) and Halliday \& Matthiessen (2004); and choices are generally organised according to their ideational (e.g. Martinec, 2001, 2004), interpersonal (e.g. Hood, 2011; Painter \& Martin, 2009; Zappavigna et al., 2008) and textual (e.g. Hood, 2011) metafunctions. While most of these studies are based on the recorded motion of the face and body in real-time interaction, this study focuses on the encoding of still body language in images. Accordingly, the interpersonal function provides 
the basis for interpreting attitudinal meanings in body language.

Guided by the principles of SFL, Kress and van Leeuwen's (2006) grammar of visual design presents an extensive description of visual resources based on examples from contemporary visual design in 'Western' cultures. Their tools provide a significant starting point from which images in other contexts can be explored. As my visual analysis deals with attitudinal meanings, the following paragraphs describe the interpersonal resources for codifying eye contact, framing and perspective in images.

The system of contact deals with whether the depicted participant is represented as having eye contact with the readers/viewers or otherwise. Kress and van Leeuwen (2006) explain that

A depicted person may be shown as addressing viewers directly, by looking at the camera. This conveys a sense of interaction between the depicted person and the viewer. But a depicted person may also be shown as turned away from the viewer, and this conveys the absence of a sense of interaction. It slows the viewer to scrutinize the represented characters as though they were specimens in a display case. (2006:43)

The proximity of the represented participants to the viewer is represented by the system of social distance, realized by the choice between close-up, medium-shot and long-shot of the participant. Van Leeuwen explains that "in pictures, as in real life, distance communicates interpersonal relationships. We "keep our distance" from strangers (if given the chance); we are "close to" our nearest and dearest; we "work closely" with someone; and so on. Distance indicates the closeness, literally and figuratively, of our relationships...In pictures, distance becomes symbolic. People shown in a 'long shot' from far away, are shown as if they are strangers; people shown in a 'close-up' are shown as if they are one of us' (2006: 138). So, distance in images is represented by the type of shot or the size of the frame in relation to the human body (Kress \& van Leeuwen, 2006, p. 124). The most common types of shot in my data are the close shot, medium close shot, medium shot and medium long shot. The description of each shot and its corresponding distance type is presented and illustrated by images taken from the corpus.

Perspective is concerned with the various depicted camera angles for representing power and involvement (van Leeuwen, 2006, p. 139) in images. According to Kress and van Leeuwen (2006) there are two types of angles, the vertical and the horizontal. The vertical or the camera height is an important means for creating symbolic power differences between participants in the image or between them and the viewer.

"If a represented participant is seen from a high angle, then the relation between the interactive participants (the producer of the image, and hence also the viewer) and the represented participants is depicted as one in which the interactive participant has power over the represented participant - the represented participant is seen from the point of view of power. If the represented participant is seen from a low angle, then the relation between the interactive and represented participants is depicted as one in which the represented participants has power over the interactive participant. If finally, the picture is at eye level, the point of view is one of equality and there is no power difference involved." (Kress \& van Leeuwen, 2006: 140).

The variables from social semiotics and social behavioral science form the basis for the systematic coding of body language in the advertisers' images. Results are discussed in terms of common and frequent patterns of features between the men and women with regard to courtship intiation behavior. Analysis will also focus on how these features cluster in the images to form various visual personae. The next section discusses body language and interpersonal attitude in interaction.

\subsection{Body Language and Interpersonal Attitude}

Generally, body language perform five types of function. These functions are to express emotions, to communicate interpersonal attitudes, to support and accompany speech, to represent identity through appearance and voice and finally to enact rituals such as greetings and praying (Argyle, 1988). With regard to interpersonal attitude, the most frequently used model is based on the work of Mehrabian $(1971,1981)$. He wrote that

"We form distinct first impressions of many people whom we meet; we feel that they are extroverted, introverted, domineering, pleasant, obnoxious, self-assured, active, argumentative, hostile, or even bland. There is something about each person, a pervasive style that applies to almost everything he or she does that enables us to form an impression before any exchange of words...the gestures or movements of these different people suggest the character or style of their personalities without the aid of words. (1981, p. 90).

Mehrabian identified two fundamental dimensions, affiliation and dominance, that can be used to explain the meanings of non-verbal behaviour in face-to-face interaction. Affiliative attitude is associated with close proximity (e.g. leaning forward), open posture (e.g. open arms and legs) and positive facial expression (e.g. eye contact and a smile). Non-affiliative attitude is shown by averting eye contact and by more distant postures that 
represent some sort of barrier to interaction, such as crossed arms and legs. Affiliative features, when they are used together, give an impression of friendliness, while non-affiliative features generally implies an unfriendly attitude. The dominance dimension refers to the extent to which a behavior is dominant versus submissive. This dimension refers to the symbolic representation of power between people. When one talks about power, the metaphors up and down are often used. For example, when someone has a high status, he or she is up in the hierarchy, while those with lesser power are normally lower down.

Mehrabian $(1971,1981)$ codified body language into two additional types of power representation in non-verbal interaction - dominant and submissive attitudes. He suggested that power could be paralinguistically represented through the expansion of personal space, realized by size (e.g. open arms as opposed to crossed arms) and height (e.g. standing as opposed to bowing). Mehrabian's work is adopted in this study as a way of codifying body language.

As gender is the focus of this study, the analysis also involves identifying non-verbal features that are frequently deployed by the men and women in their images, what the patterns mean interpersonally and what they visually reveal about gendered behaviour. Section 2.3 explains the relationship between gender and body language in images.

\subsection{Body Language and Gender Relations}

Erving Goffman (1979) believed that gender and gender relations are socially defined and constructed and that these are projected in images that we see daily. He distinguished five dimensions by means of which unequal power relations between genders could be identified: relative size (i.e. women shown smaller or lower, relative to men), feminine touch (i.e. women constantly touching themselves), function ranking (i.e. lesser occupational role), ritualization of subordination (i.e. the tendency to be recumbent), and licensed withdrawal(i.e. detachment from a scene via averted gaze). These dimensions are realized through various non-verbal features such as hands and legs orientation, facial expression and head orientation. The most relevant for my analysis are his realizations of the 'feminine touch'(i.e. fingers/hands touching object or self) and his canting postures, specifically the 'knee bend', 'body cant' and 'head cant' (see Figure 2). These non-verbal behaviours are found in my corpus, and Goffman's terms provide a way for classifying body language in this study.

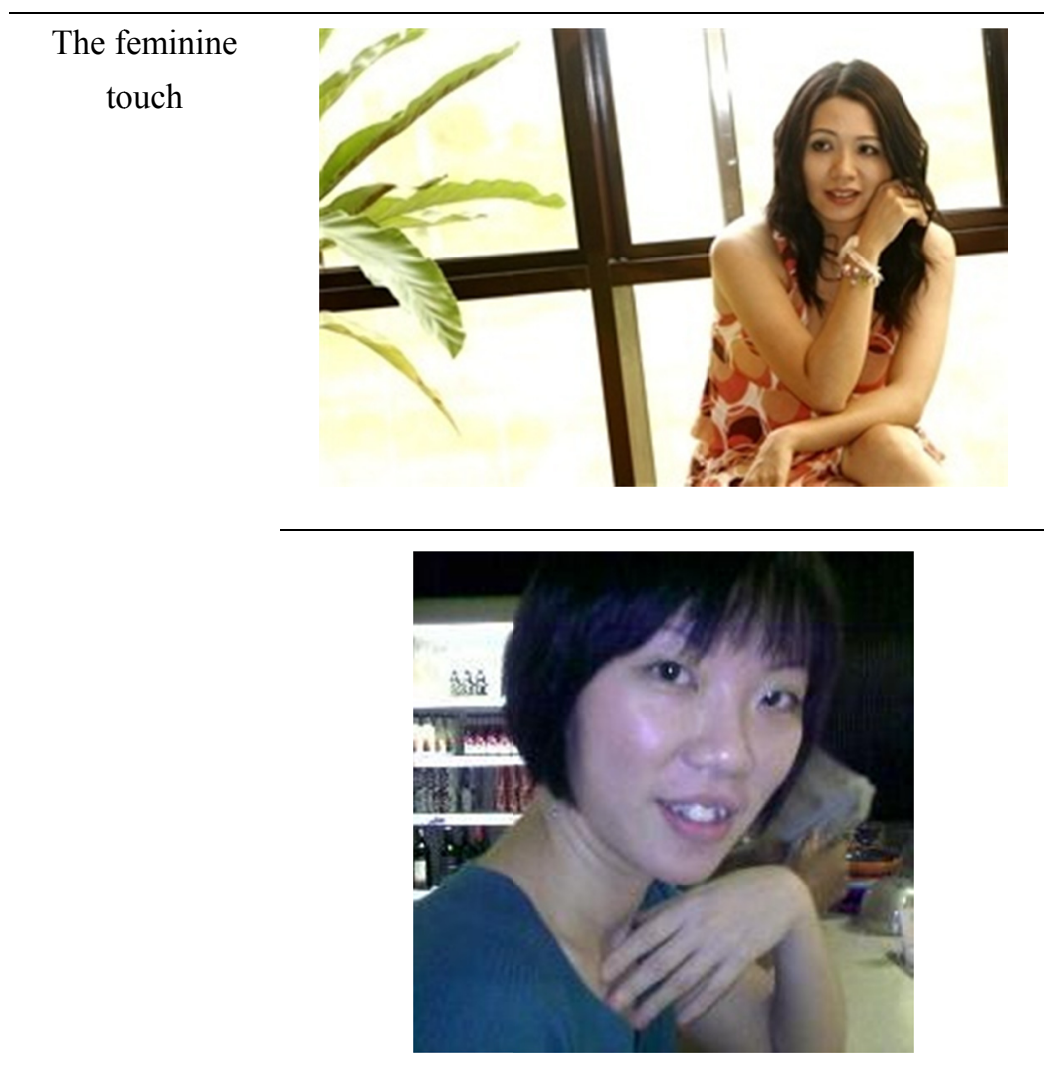




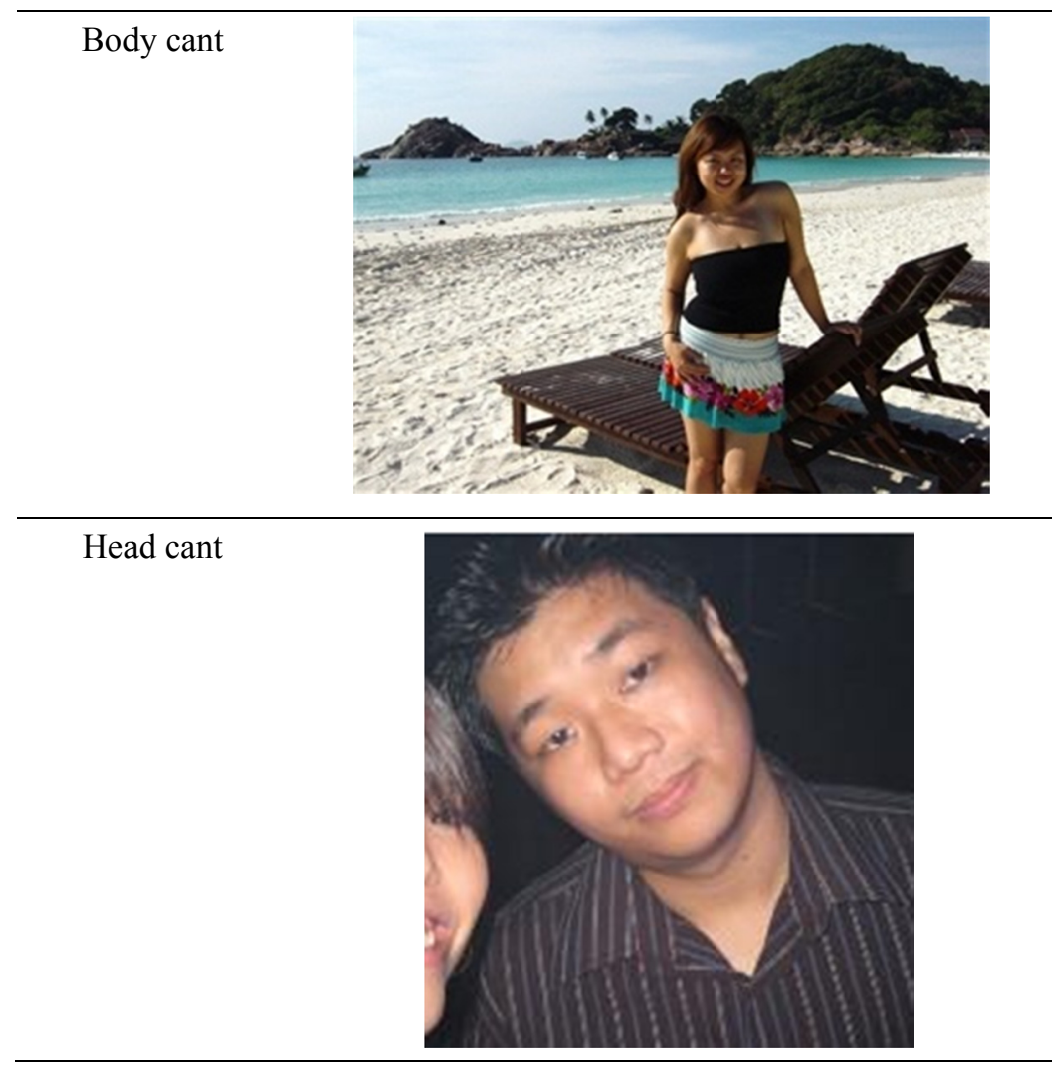

Figure 2. Examples of the feminine touch, the body cant and the head cant

The next section looks at the non-verbal representations of courtship initiation behaviour by women and men.

\subsection{Non-verbal Representations of Courtship Initiation Behaviour}

Courtship initiation behaviour is realized through a configuration of non-verbal signals, identified by several studies as repertoires of facial expressions and gestures. The following findings by Grammer (1989) capture some of this non-verbal repertoire,

"Females seem to attract attention by displaying subtle, nonverbal solicitation, which is characterized by eye-contact immediately followed by looking away, special postures and ways of walking, pouting, eyebrow flashing, primping, smiling, head tossing, neck presentation, nodding, hair flip, gaze fixation, room-encompassing glance, lip licking and 'dancing' in the chair." (Grammer in de Weerth \& Kalma, 1996, p. 178, my bold)

Another quote by Whitty (2003) stressed the significance of features such as head orientation and facial expression in the act of flirting,

The basic code of kinetic gestures would include, in particular among women, phenomena such as tossing one's hair so that one's face is tilted upwards and one's neck is exposed. Women also often lick their lips, or pout to indicate attraction ... Flirtatious behaviour often consists of demure glances downward, a short darting glance (glancing at a person one is attracted to for a few seconds, glancing away, then looking back again), and eyebrow flashes (the raising of both eyebrows for a couple of seconds, usually accompanied by a smile and eye contact) (Whitty, 2003: 342, my bold)

Based on these typical behaviours, Givens (1978) suggests that offline courtship behaviour often relies on nonverbal signs of submissiveness (e.g. being shy and non-threatening) and affiliation (e.g. being approachable and friendly). He explains that

"Flirtatious behavior appears to be determined by attentional, submissive-affiliative, and childcare-related nonverbal signs, which have evolved in order to lower aggression and elicit affectionate responses in the individuals." (Givens in Weerth \& Kalma, 1996: 178)

Accordingly, deployment of a submissive, affiliative pose cluster would be the ideal non-verbal performance in enacting an engaging, non-threatening persona that could 'elicit affectionate responses' from potential partners. 
However, two features in particular are frequently observed and are essential in the act of courtship initiation: eye contact and a smile. Deployed together, this cluster of two features represents affability and engagement. While these are realizations of courtship initiation behaviour in face-to-face encounters, the question is 'are these non-verbal performances replicated in the advertisers' poses?'. The following section describes the method for this study.

\section{Method}

Meanings related to expressions of attitudes can be distinctly expressed through facial expression and posture as demonstrated by the four advertisers in Figure 3.0. Positive and negative attitudes can be conveyed through facial features, head orientation, arm orientation and body position.

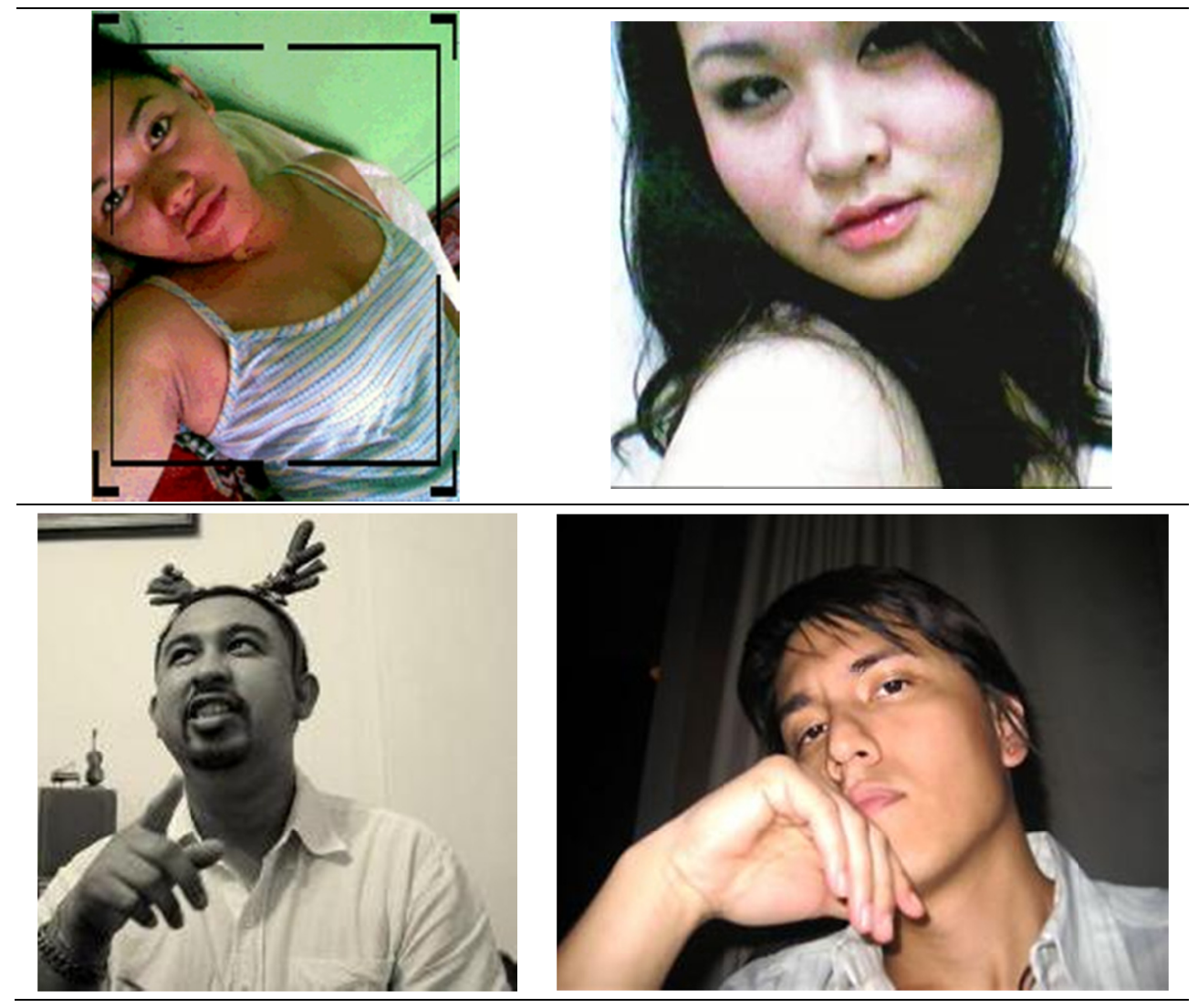

Figure 3. Four expressions of attitude by four advertisers

While the body language of the majority of advertisers is found to express a friendly attitude, some body language appears to convey a sense of aloofness. Interestingly, a few stances do appear deliberately flirtatious. Body language can trigger positive or negative first impressions of people we see or meet; it 'suggest(s) the character or style of their personalities without the aid of words...' (Mehrabian, 1981: 90). Accordingly, how the advertisers represent themselves in their personal photographs is important in triggering the right first impression and eventually a written response. Given this, it is hypothesized that both women and men will visually perform affiliative acts through a distinctive combination of body orientation and facial expression. These bodily performances are what I have termed as a POSE. Accordingly, a pose in this study is defined as a cluster of non-verbal features that are deployed in photograph for attitudinal effect. The clustering of body language features is based on their grouping as one interconnected unit of the human body. For example, when describing the system of POSTURE, the positioning of the body (see 1.1 and 2.3), head orientation and facial features form one cohesive unit, and are thus clustered into one system. Each of these non-verbal features will form the basis for the systematic annotation of body language in the corpus of images. The frequency occurrence of these features will be presented in the findings section.

\subsection{The Corpus}

The corpus for this study consists of 200 personal advertisements placed by Malaysian men from the age of 
22-36 and women from the age of 20-32 (Note 1) selected from a dating website called my.match.com. This site was selected as a source for personal ads for two reasons. First, it provides free (but limited) access to its users and secondly, the site claims to have 8 million members worldwide and to be visited by over 300,000 people a month. Individual profiles are available online, and are free to public view. The terms and conditions of the site state that personal information posted on the site is considered non-confidential and non-proprietary. However it cannot be used in connection with any commercial activities. These adverts constitute the specialized corpus (Hunston, 2002; Baker, 2006) that has been compiled to study a particular variety of language (Baker, 2006) and therefore aims to be representative of this particular type of text (Hunston, 2002). This corpus comprises 580 images authored and posted by the 200 Malaysian advertisers. The total number of images is 580, 276 from female profiles and 304 from male profiles.

\subsection{Facial Variables}

To frame the current investigation of body language further, I am adapting the variables proposed by Tian (2010) for identifying specific facial variables in images. These variables capture the basic facial features of the advertisers and form the key elements needed for analysing facial expression. The semantic concepts of 'up' and 'down' are understood as realizing and characterizing the emotions of happiness or sadness in her study. Each expressive element defines a meaning, for example up-curved lips, raised eyebrows and raised cheeks are associated with positive affect, while down-curved lips, eyebrow and cheeks are associated with negative affect. The variables that I am adopting from Tian's network of facial articulation are MOUTH ORIENTATION, MOUTH APERTURE (see Figure 4) and HEAD ORIENTATION (see Figure 5).

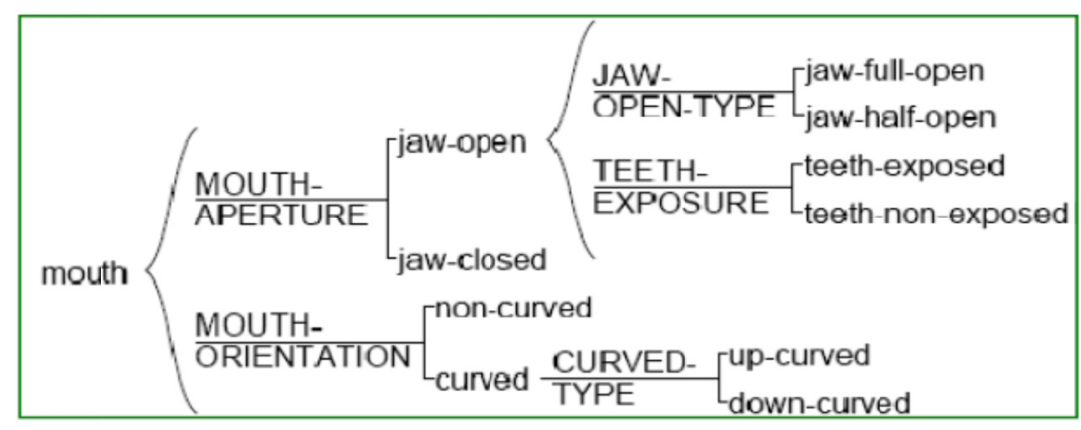

Figure 4. Mouth Orientation and Aperture

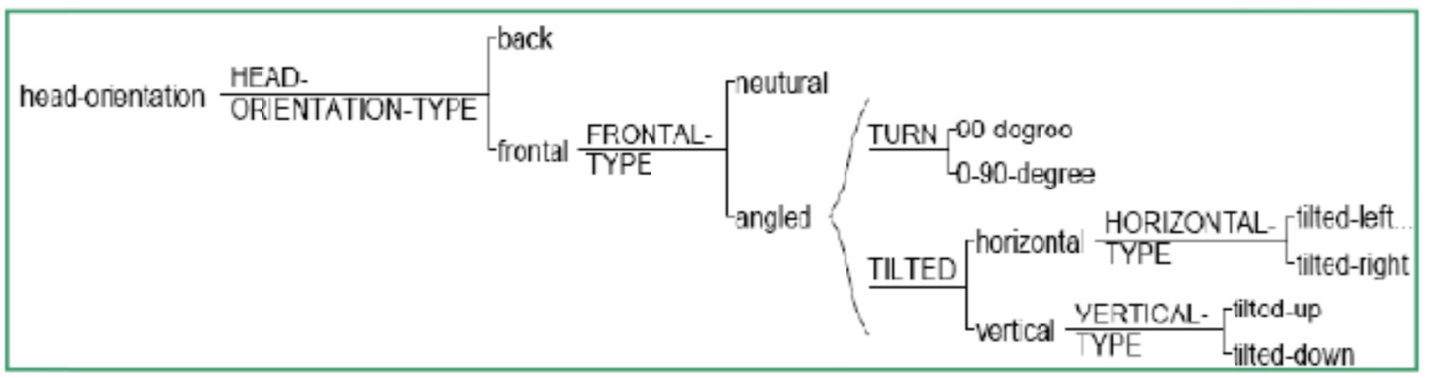

Figure 5. Head Orientation

The framework for analysis also integrates features from work on visual grammar by Kress \& van Leeuwen $(1996,2006)$ specifically interpersonal resources for codifying eye contact, framing and perspective in images. These variables are instrumental in representing social relations between the participant in the image and the viewer (see section 2.1). The act of looking at the camera forms a vector or a line connecting the eyes of the participant and the viewer and establishes an imaginary contact between the actor and the viewer, while the act of looking away, of not having eye contact, represents an imaginary absence of involvement. Additionally, 'in pictures, as in real life, distance communicates interpersonal relationships' (Kress \& van Leeuwen, 2006). The proximity of the represented participants to the viewer is represented by the system of SOCIAL DISTANCE, realized by the choice between close-up, medium-shot and long-shot of the participant. Finally, perspective refers to the various depicted angles that express two aspects of the represented social relation between the viewer and the 
represented participant: power and involvement (van Leeuwen, 2008: 139) (see section 2.1).

The features of pose i.e. posture, facial variables and perspective will form the basis for the systematic coding of body language in the advertisers' images using the UAM image tool program (O'Donnell 2008). In terms of assigning interpersonal meanings to the body language cluster, Mehrabian $(1971 ; 1981)$ proposes two main dimensions that have consistently been used to interpret and assign attitudinal meanings to clusters of non-verbal behaviour in interaction. These dimensions are affiliative vs. non-affiliative and dominant vs. submissive and will form the basis for interpreting clusters of body language features into different representations of visual identities. Additionally, these clusters will be quantified to form the basis for comparison between the men and women in courtship initiation behaviour.

\section{Results and Discussion}

This section discusses the realizations of courtship initiation behaviour in the men and women's personal ad images. Findings reveals that many of the non-verbal realizations of face-to-face courtship behaviour can indeed be observed in the advertisers' poses.

I shall first focus on the women's images. The following three female images in Figure 6. display some of the non-verbal courtship initiation behaviour

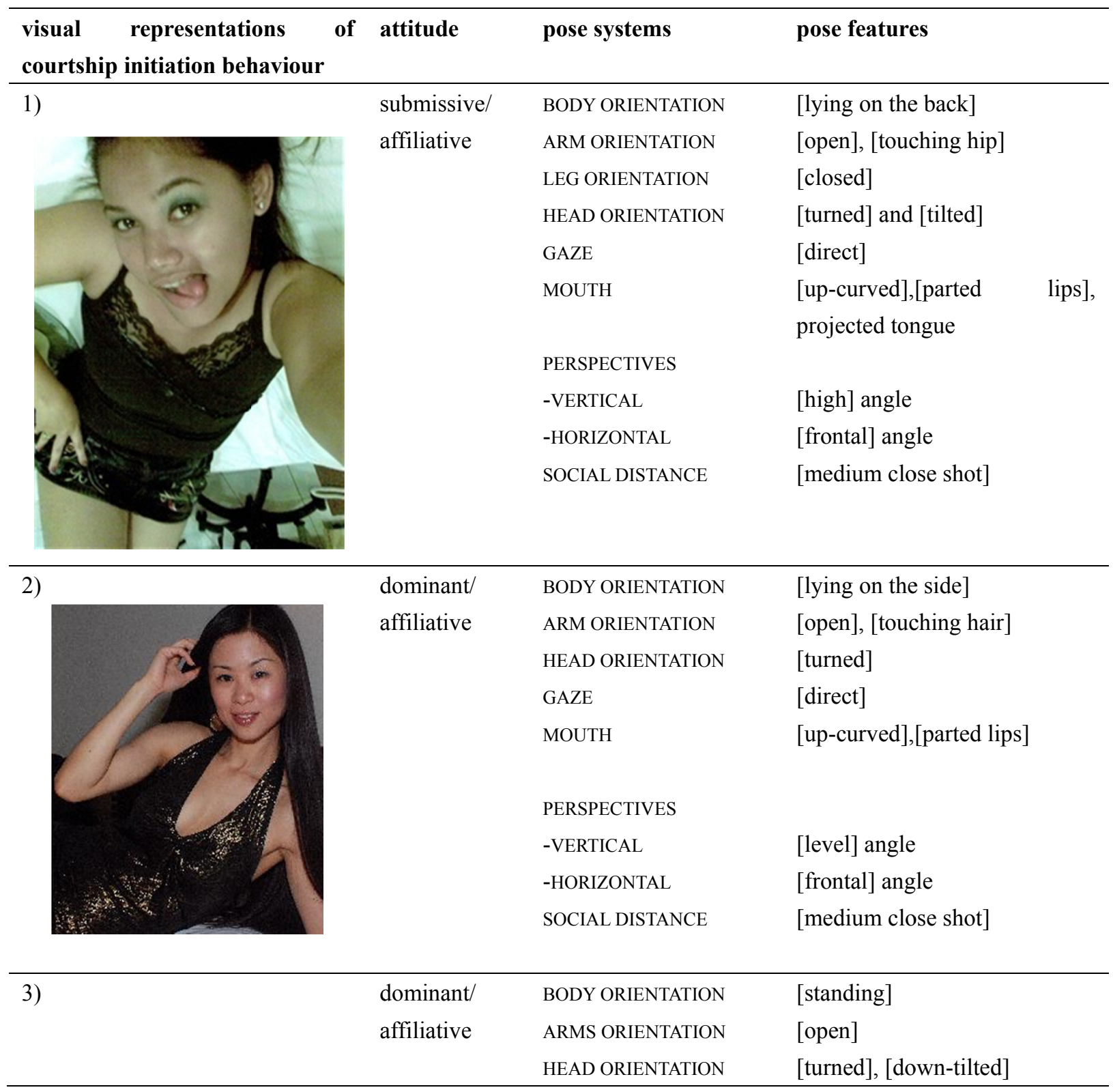




\begin{tabular}{lll}
\hline GAZE & $\begin{array}{l}\text { [direct] } \\
\text { MOUTH }\end{array}$ & \\
[puckered],[lips closed] & \\
PERSPECTIVES & -VERTICAL & [level] angle \\
[oblique] angle & -HORIZONTAL & [medium close shot] \\
& SOCIAL DISTANCE & \\
& & \\
\hline
\end{tabular}

Figure 6. Visual representations of courtship initiation behaviour

Focusing first on similarities, all of the participants maintain eye contact, display the up-curved mouth shape signifying a smile, assume an open body orientation suggesting approachability and in terms of framing, are captured from the waist up, a medium close shot. Differences, however, can also be observed. The participant in image (1) is photographed from a high angle, representing her as submissive, while the other two are taken from a level angle. Three contrasting mouth orientations are displayed. Although they all represent positive affect, the orientation in (2) is affiliative (i.e. friendly), while the tongue in (1) and the pout in (3) are both sexually suggestive. To substantiate this claim, Figure 7 compare mouth orientations in images (1) and (2) with mouth orientations in two kissing acts.
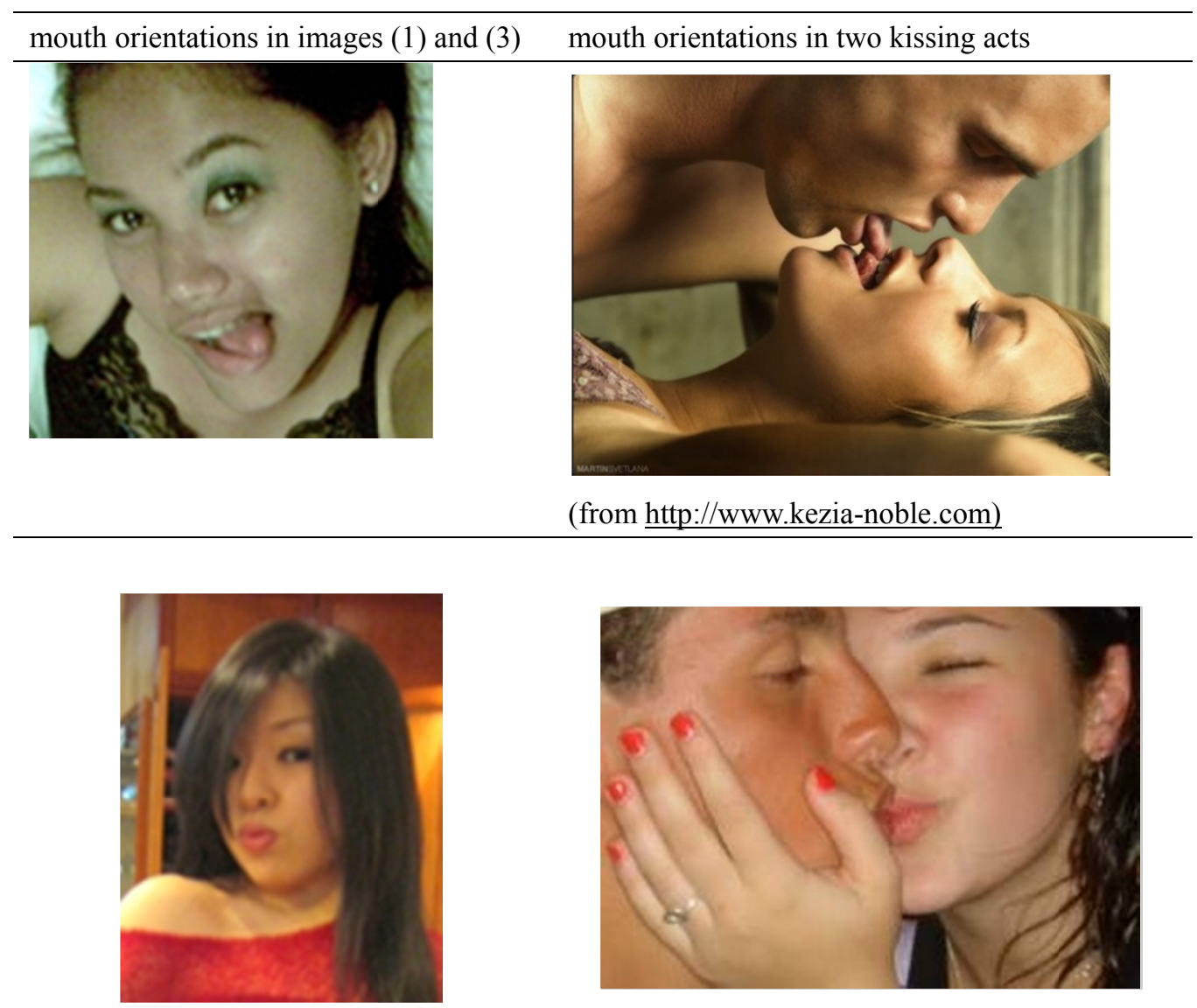

(from http://www.luvcube.com)

Figure 7. Suggestive mouth orientations

Frequency analysis of pose features reveals that the most dominant cluster realizing affiliative behaviour is a combination of direct gaze and an up-curved mouth shape such as in Figure 8), similar to the one displayed by 
the participant in image (2). $83 \%$ of mouth orientation is realized in the form of an up-curved shape with $72 \%$ of these are assumed with parted lips (as demonstrated in images 4-6 below), suggesting positive emotion and friendliness.

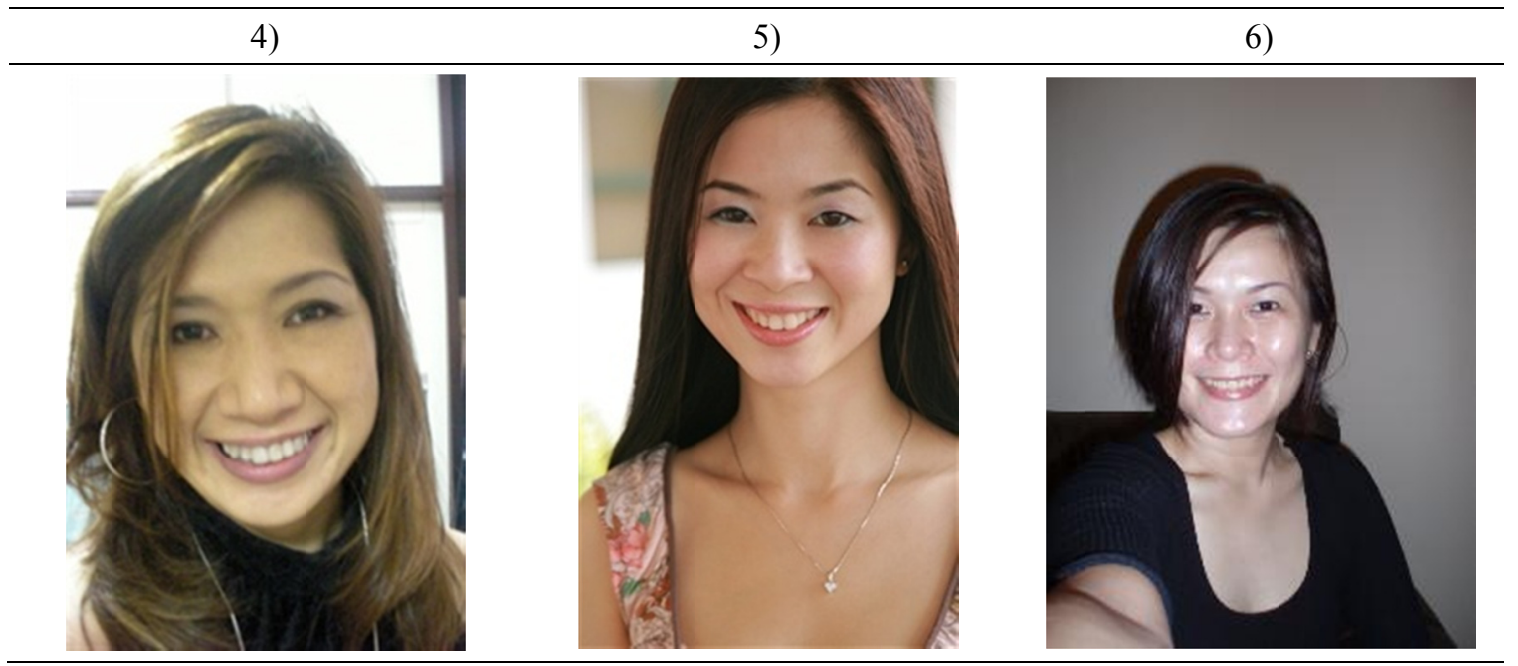

Figure 8. Visual representations of affiliative behaviour among the female advertisers

Averted gaze forms only $9 \%$ of the total gaze type, but three-quarters of these representations are coupled with a smile, illustrated by the participants in images (7-9) below. The most common type of smile instantiated with the averted gaze occurs with the lips closed rather than parted. This cluster of features, both in the type of gaze and smile deployed, suggests some restraint in their behaviour; a kind of submissiveness and shyness, especially when coupled with a down-tilted head orientation. The cluster appears to show some likeness to the behaviour observed by Whitty (2003) when she described that:

"Flirtatious behaviour often consists of demure glances downward, a short darting glance (glancing at a person one is attracted to for a few seconds, glancing away, then looking back again)...usually accompanied by a smile and eye contact..." (emphasis added)

This cluster of a 'darting glance' (shown as a sideways glance) in image (7), downward glance in image (8), and eye contact and a smile in image (9) can be observed in the images below (see Figure 9).

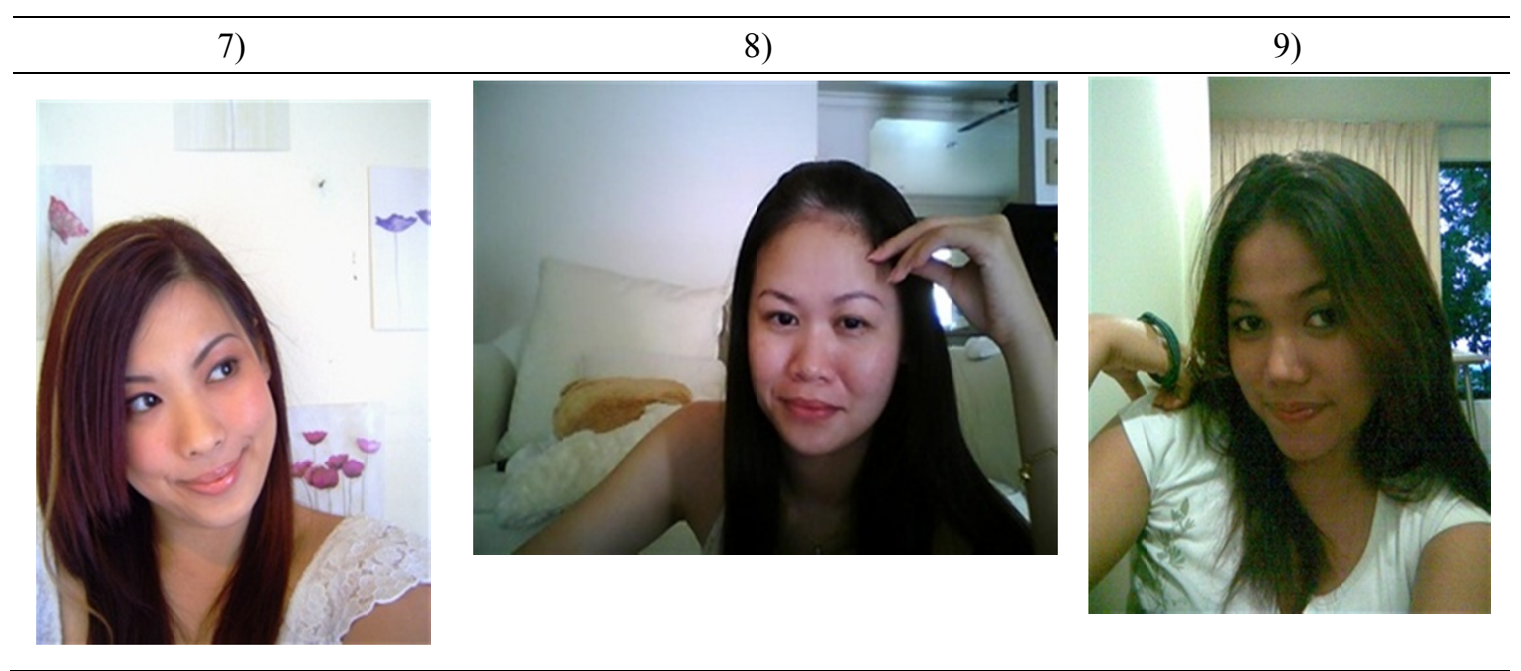

Figure 9. Visual representations of flirtatious behaviour among the female advertisers

Similar to the women's images, the most common realization of courtship initiation behaviour in male images is 
the cluster of affiliative features suggesting friendliness (i.e. direct gaze and up-curved mouth shape). Frequency analysis of features reveals that $65 \%$ of mouth orientation is realized in the form of the up-curved shape and of this $65 \%, 80 \%$ of up-curved mouth shape is coupled with a direct gaze. Additionally, $61 \%$ of these smiles are performed with parted lips. The following sequence of images 10-12 in Figure 10, illustrate the cluster of up-curved mouth shape, lips parted and direct gaze.

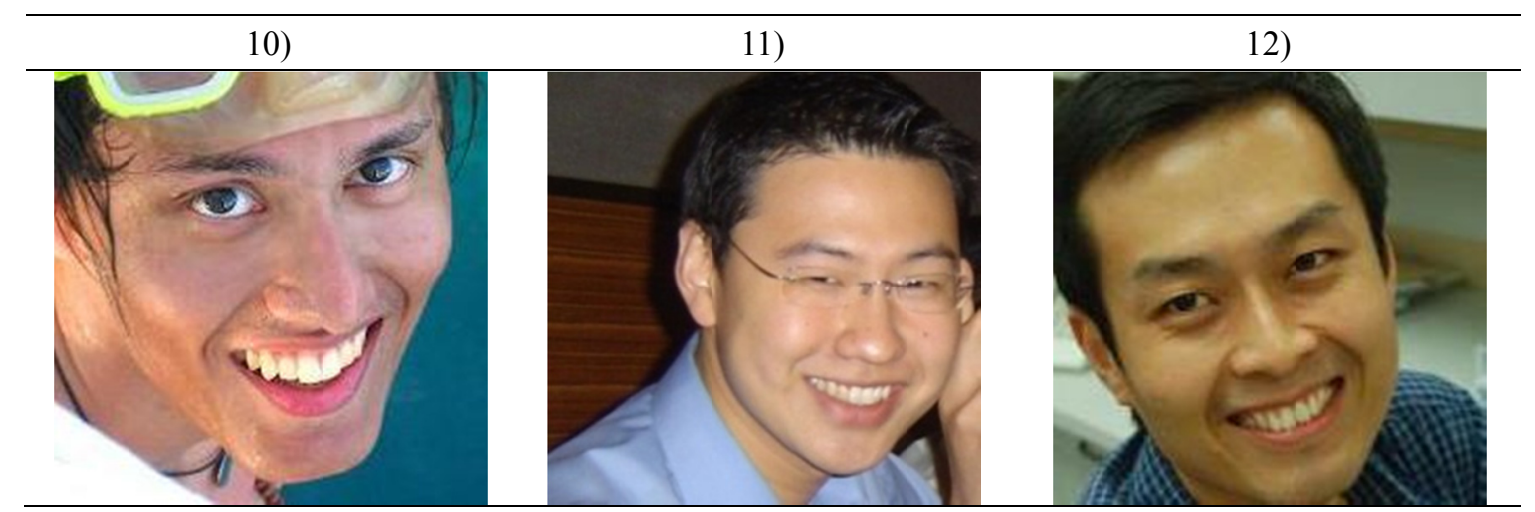

Figure 10. Visual representations of affiliative behaviour among the male advertisers

There are twice as many neutral mouth shapes where the lips are in a position of rest and not pulled in any direction displayed in the men's images $(22 \%)$ as in the women's $(11 \%)$. The attitude projected by the neutral shape is a non-affiliative one. Coupled with a direct gaze and level angle, the cluster can be taken as construing a reserved persona. Engagement is implied through eye contact and power relations between advertisers and the viewers are equal, but the absence of a smile and of visual positive affect suggests a lack of interest on the participants' part, as shown in the following three images in Figure 11.

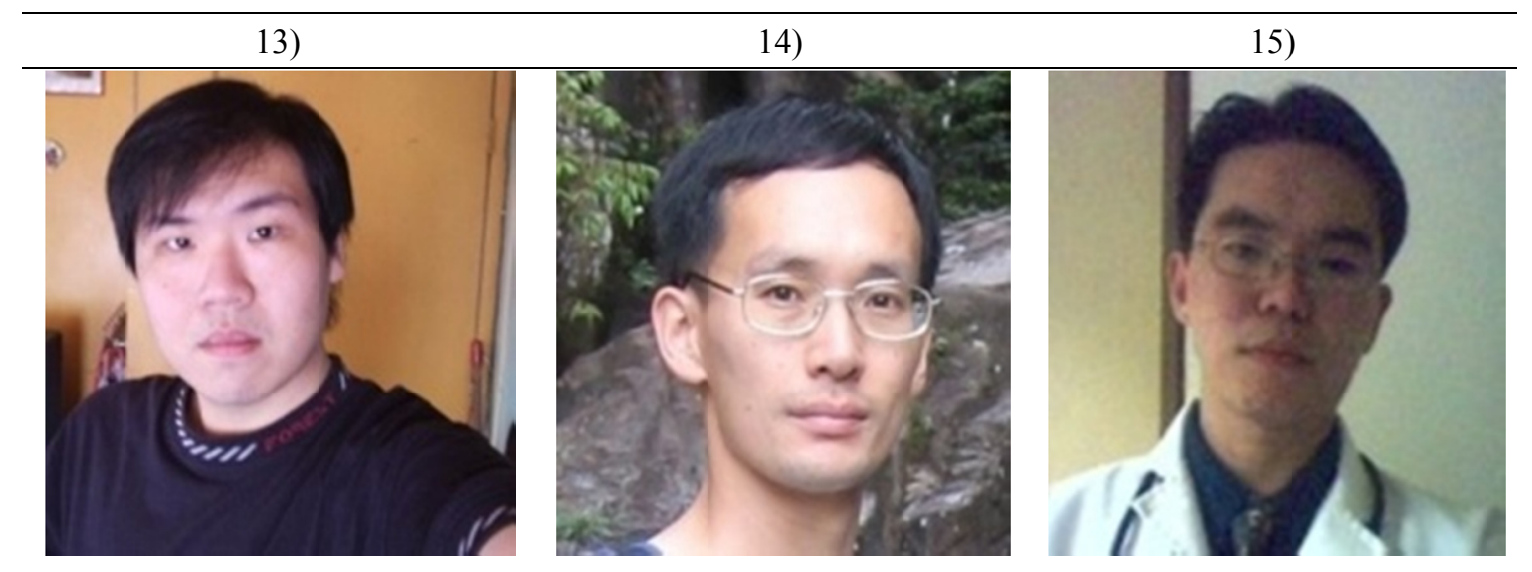

Figure 11. Visual representations of non-affiliative behaviour among the male advertisers

If the above participants are reserved in their non-verbal representations, the advertisers in images (16) and (17) appear aloof while image (18) appears intimidating in their attitudes due to the cluster of direct gaze, down-curved mouth shape, low vertical angle and open body orientation (Figure 12). This cluster of features, made more prominent by the type of angle and mouth orientation, suggests a combination of dominant and non-affiliative attitude that is normally deployed in threatening situations, perhaps as a mark of dominance or defiance. In a face-to-face courtship initiation ritual however, rarely does one indicate interest through this cluster of dominant and non-affiliative body language. While the reserved personae in images (13-15) is also enacted by the women, the defiant and dominant stance in images (16-18) is not displayed in the women's images. This dominant stance arguably performs a complementary role to the submissive demure stance displayed by some of the women (see images 7-9) in Figure 9). 


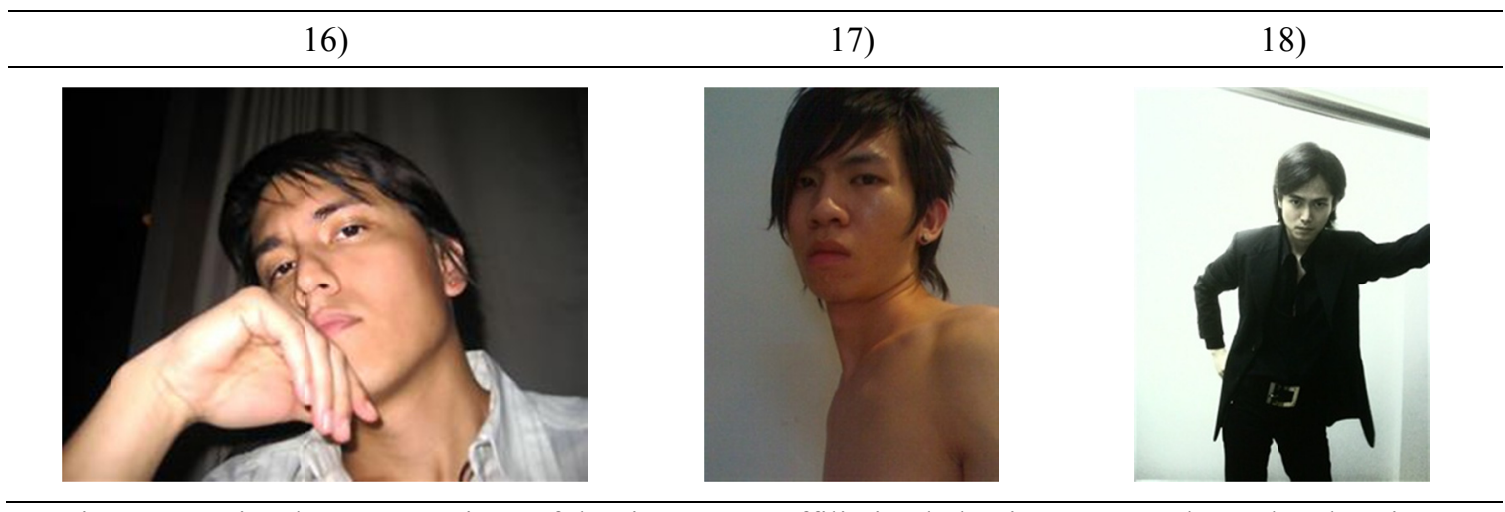

Figure 12. Visual representations of dominant, non-affiliative behaviour among the male advertisers

The averted gaze, the up-curved mouth and closed lips cluster is not as common among the men as it is among the women (images 7-9). Images (19) and (20) in Figure 13 are two representations of this cluster found in the men's data. The combination of the up-curved mouth shape and the close proximity features suggests positive affect and involvement, but the averted gaze and the oblique angle suggests a sense of detachment. The combination of the wanting and the holding back appears to capture what is characterised by Givens (1978) as the 'tentative and hesitant approach' in the first phase of courtship initiation behaviour.

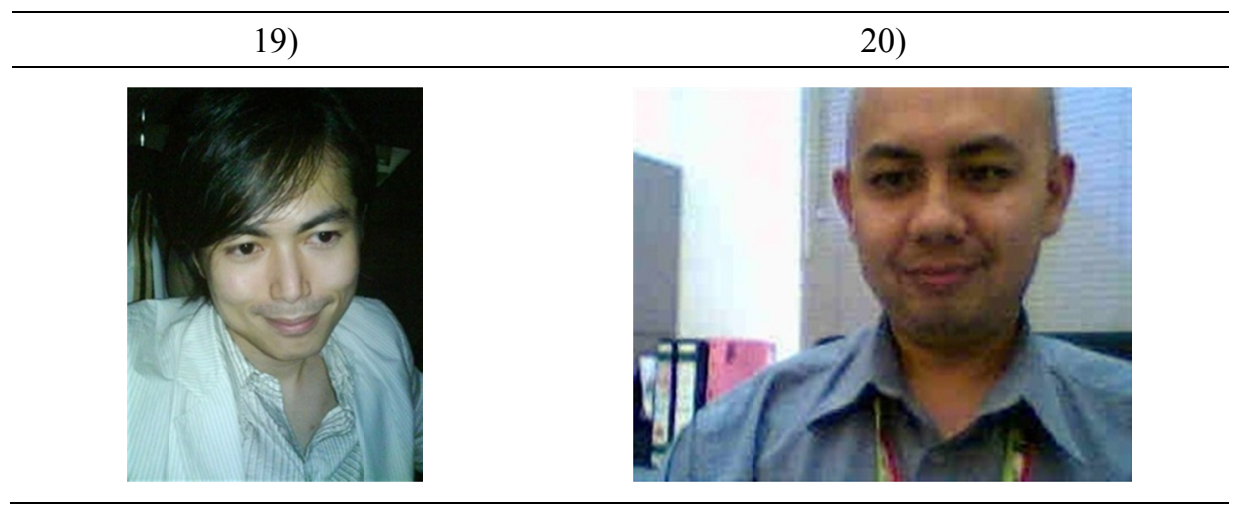

Figure 13. Visual representations of affiliative, submissive behaviour among the male advertisers

Realizations of playful behaviour in the men's images also occur in Figure 14. Realizations comprise a cluster of affiliative features to represent a friendly attitude through up-curved (image (21) \& (22) or puckered mouth shape (image (23)), direct or averted gaze and level or low angle. Humorous behaviour in the images appears to be realized by some kind of hand gesture involving a prop (i.e. pointing in image (21) and holding an object in (22) and (23)). Additionally a prop (i.e. the antler) is also used in image (21); though instead of holding it like the other two participants, this advertiser wears it on his head. All three appear animated, engaging the viewers in a comical display of behavior construed by means of affiliative expression, closed arm orientation (placed near the body) and circumstances of accompaniment.

\section{1)}

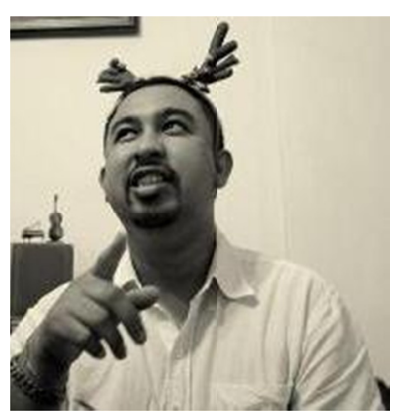

22)

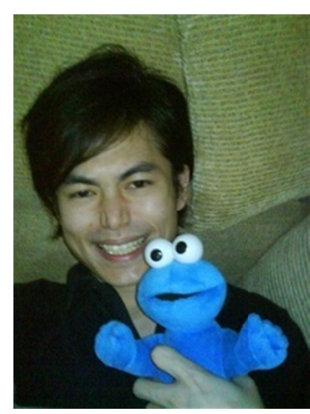

23)

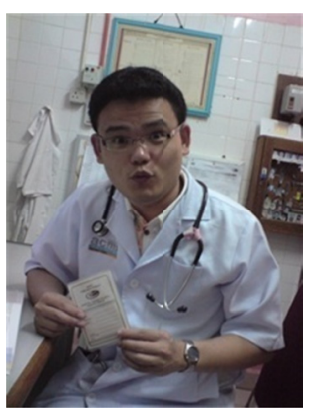

Figure 14. Visual representations of affiliative behaviour among the male advertisers 
It is also interesting to compare the classic flirtatious realization of the 'pout' as it is performed by female and male advertisers in images (24), (25), and (26) in Figure 15. The puckered shape is distinctive and similar in all three mouth orientations. However, three pose features differentiate these visual performances: head orientation, arm orientation and horizontal angle. It appears that the features of down-tilted head orientation, the sideways gaze, the raised shoulder and the oblique angle are contributing to the flirtatious meaning of the pout in images (24) and (25). This solicitation posture is made up of a combination of dominant and submissive cluster of features. On the other hand, the cluster of features accompanying the puckered lips in image (26) appears to enact a different meaning. His raised eyebrows, wrinkled forehead and gesture of showing a piece of card, represents his behaviour as a funny rather than flirtatious act. What this shows is that the interpersonal meaning of the pout, as demonstrated in the images below, must be read in conjunction with the cluster of features that are deployed with it.

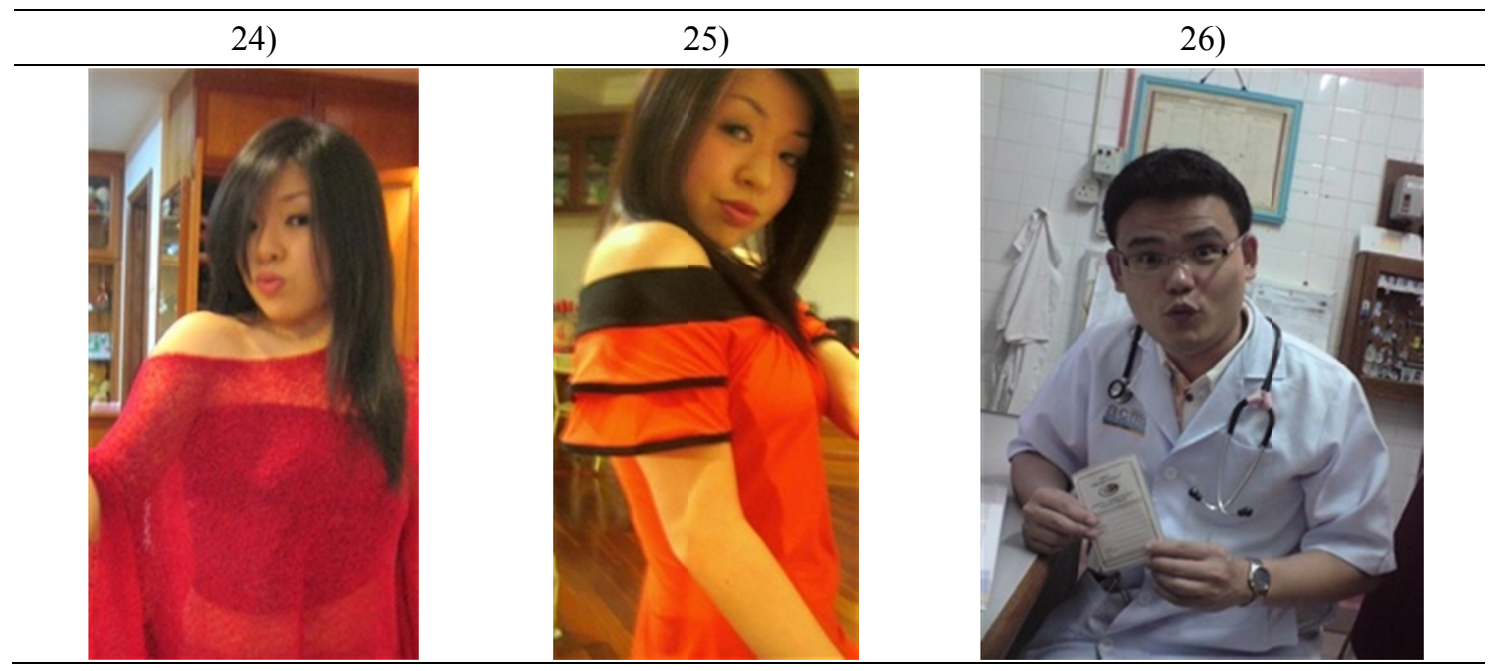

Figure 15. Visual representations of the 'pout' by the advertisers

Gaze plays a very important role in representing interpersonal engagement with the viewers. On the whole, the results revealed a similar percentage in the frequency of eye contact among the male $(86 \%)$ and female advertisers (89\%). The cluster of direct gaze and up-curved mouth was also instantiated as frequently by the men $(81 \%)$ as well as women $(80 \%)$. The high frequency of this affiliative cluster may be due to the luring role of personal advertisements.

Although Goffman (1979) finds that head canting is a typical female behaviour in his data (recall that submissive behaviour is associated with the act of lowering one's body features), my data analysis revealed otherwise. There is only a slight difference in percentage in head canting between men (32\%) and women (35\%). Men engage in head canting almost as frequently as women. However, women assume the down-tilted head position more frequently than men, while men display the up-tilted orientation more often. Within the fields of sociology and media, head tilting/canting has been described as a gesture of submission and a way to ingratiate oneself by reducing one's overall height (Goffman, 1979). Despite this recurrent theme of submission in interpretation, two studies of body posture in photographs from psychology reveal that a person is judged as more attractive and pleasant in images when their head is tilted than when upright (Otta et al., 1994; Costa \& Bitti, 2000). Given what we know of courtship initiation behaviour, and if head tilting is considered as a submissive but yet a 'pleasant' orientation, then this seems to explain why this feature is enacted frequently by the women as well as by the men (see Figure 16). 
cluster of direct gaze, up-curved mouth and head tilting in the men's images

27)
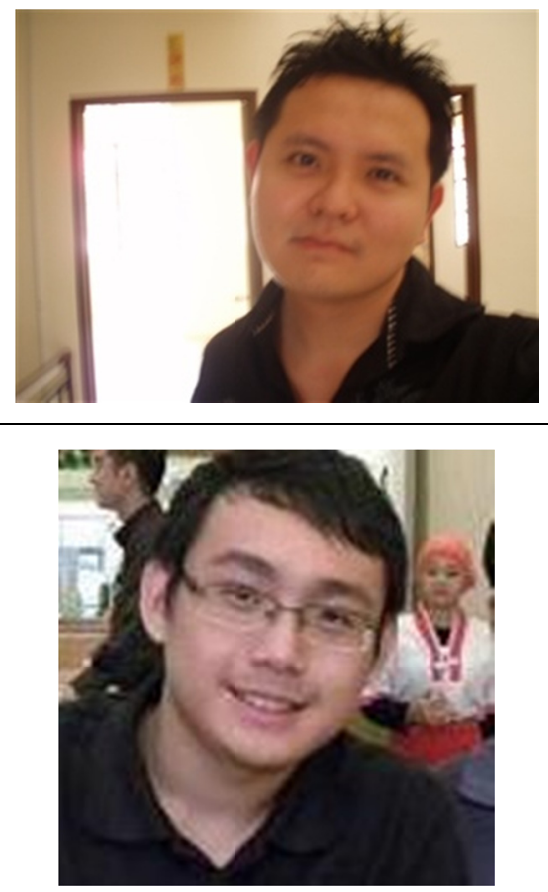

cluster of direct gaze, up-curved mouth and head tilting in the women's images

29)

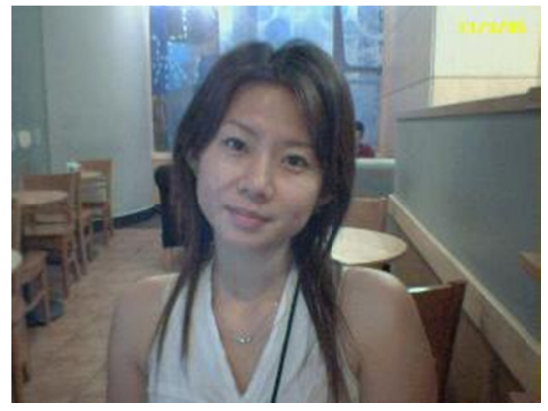

Figure 16. A cluster of direct gaze, up-curved mouth and head tilting by the male and female advertisers

The following Table 1 displays the summary of affiliative and unaffiliative pose features between Malaysian male and female advertisers.

Table 1. Affiliative and unaffiliative pose by Malaysian male and female advertisers

\begin{tabular}{|c|c|c|c|}
\hline & & Men & Women \\
\hline \multirow[t]{3}{*}{1} & The affiliative pose (friendly) & & \\
\hline & Direct gaze + upturned mouth & $81 \%$ & $80 \%$ \\
\hline & Direct gaze + upturned mouth + Head canting & $32 \%$ & $35 \%$ \\
\hline \multirow[t]{2}{*}{2} & The affiliative pose (flirtatious) & & \\
\hline & Averted gaze + upturned mouth + down-tilted head orientation & - & $9 \%$ \\
\hline \multirow[t]{2}{*}{3} & The unaffiliative pose (reserved) & & \\
\hline & Direct gaze + neutral mouth shape + level angle & $22 \%$ & $11 \%$ \\
\hline
\end{tabular}

The following two images in Figure 17 are taken from a paper entitled 'Flirting Fascination' by Rogers (1999), and capture the behaviours in the first stage of courtship initiation for gaining attention and showing interest. A cluster of affiliative-submissive features is marked in yellow. These features are highlighted to demonstrate the similarities between non-verbal features activated in a face-to-face environment and features identified in the online images. 
Face-to-face courtship initiation ;

The 'attraction' phase (Givens 1978) - signaling interest and attraction

realizations

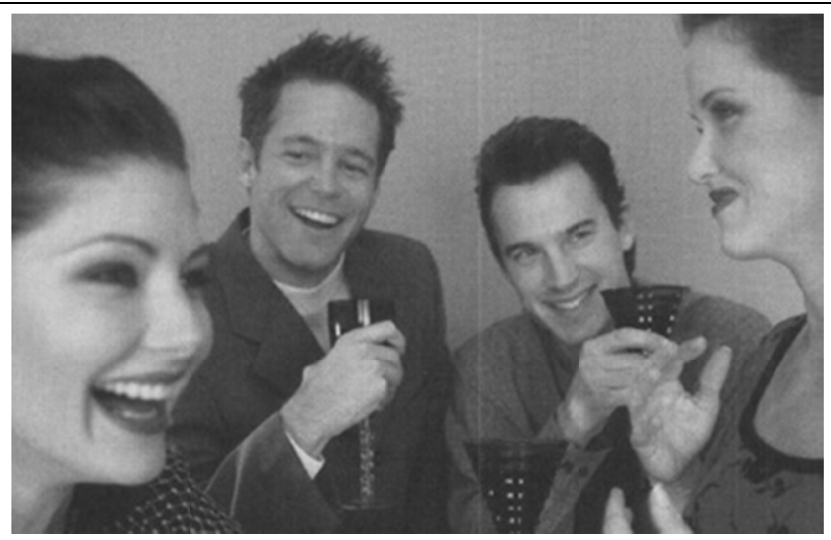

[direct gaze]

[up-curved mouth], [parted

lips]

[side-tilted] head orientation

[closed] arm orientation

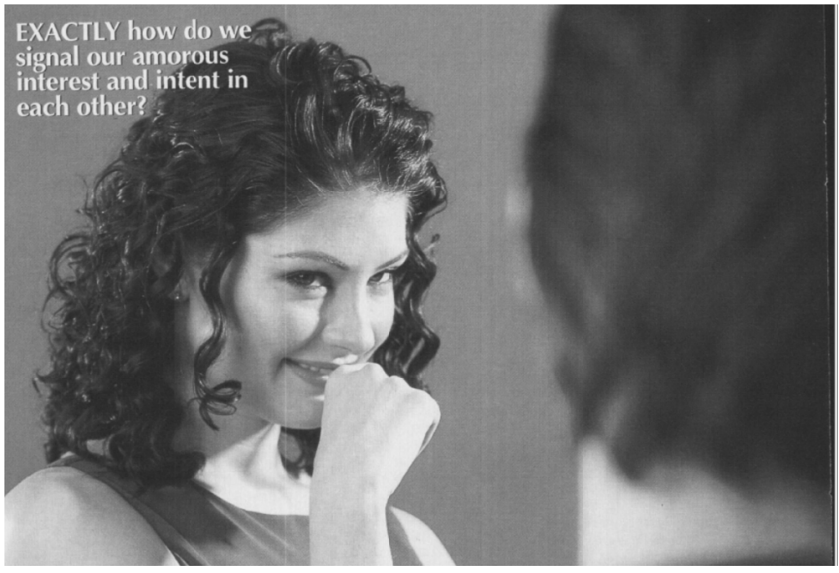

[direct gaze]

[up-curved mouth], [parted

lips]

[down-tilted] head

orientation

[closed] arm orientation -

[touching lips]

Figure 17. Face-to-face courtship initiation behaviours for gaining attention and showing interest

My results revealed body language features among men and women that appear to replicate typical face-to-face courtship initiation moves. Characteristic patterns of pose features realizing the 'attraction' phase and their associated dimensions in both sets of men and women's images are listed in Table 1.0 below.

Table 2. Dominant patterns of pose features realizing the 'attraction' phase in the images

\begin{tabular}{ll}
\hline dominant patterns of realizations in the images & dimension \\
\hline direct gaze & affiliative and dominant \\
up-curved mouth shape & affiliative \\
tilted or turned head orientation (either sideways and down) & submissive \\
level or high camera angle & \\
frontal body angle & equal or submissive \\
& affiliative \\
\hline
\end{tabular}

Of these realizations, the most typical cluster of pose features involves the direct gaze, the up-curved mouth and the parted lips, as demonstrated in the following two images (Figure 18), representing an affiliative or friendly attitude. 
common cluster of pose features : the [direct gaze], [up-curved mouth shape] and [lips parted]

31)

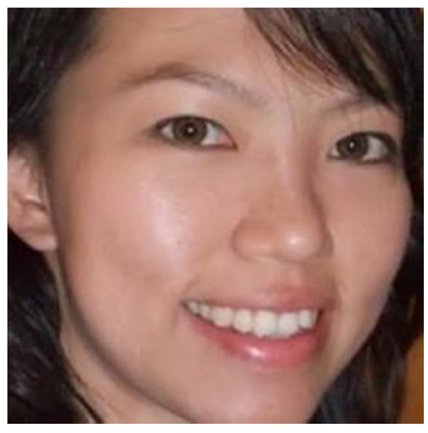

32)

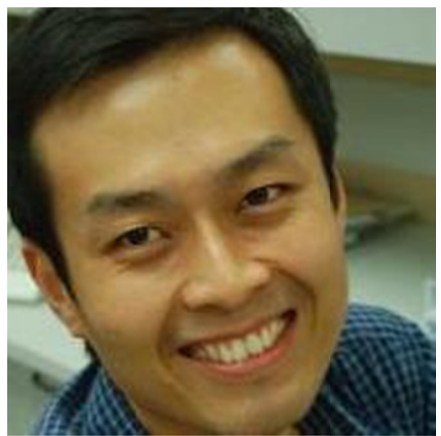

Figure 18. Typical cluster of pose features

Additionally, as described in earlier paragraphs and exemplified by accompanying images, the flirtatious, the reserved, the desiring but hesitant and the playful types, construed by means of different pose clustering, are also found in the images.

Recall that the main aim of a personal ad is that of 'selling' the persona for the purpose of attracting a potential other. Accordingly, results of UAM annotation reveal that features of friendliness - direct gaze, up-curved mouth shape and close shot - are the most frequently instantiated features in the men and women's images. Overall, these elements are represented in $68 \%$ of the women's images and $65 \%$ of the men's. Images are represented in ways that encourage involvement and enhance the advertisers' physical attractiveness. Smiling has been found to enhance attractiveness (Mehu et al., 2008), and results reveal that the men and women display more smiles in their images. Additionally, there are also more eye contact between the represented advertiser and the viewers in the images. Alongside the aim of 'selling' oneself, what the advertisers are also attempting is to negotiate a relationship, which is akin to the concept of 'flirting' in a courting process. Results have shown how the 'attraction' stage of flirting in both online and face-to-face contexts is carried out in similar ways, using similar strategies involving the body. Both women and men visually perform flirtatious acts through a distinctive combination of body orientation and facial expression.

It was found that regardless of gender, realizations of the dominant, affiliative stance, specifically the up-curved mouth shape and direct gaze, are frequently instantiated in the images. However only $62 \%$ of men compared to $86 \%$ of women smiled in their images. Accordingly, these findings appear to support earlier studies (Goffman, 1979; Hall \& Friedman, 1999; Gallant et al., 2011) that found women in general tend to smile more often than men in their photographs and in other contexts. There are more displays of closed arm orientation in both sets of corpora. Women however appear to instantiate touching gestures $(66 \%)$ slightly more frequently than men $(50 \%)$. Interestingly though, touching the hips is a common feature among the men and women, whereas women are found to hold objects twice more often than the men. Goffman (1979) found this non-verbal touching and holding behaviour commonly instantiated by the women in his data and has termed this as 'the feminine touch'.

Further to these results, men are found to use a low vertical angle more frequently than women, emphasizing dominance over the viewers; as aforementioned, low camera angle is used to increase the perception of participant's height and make them more commanding in appearance. Contrastingly, twice as many women's images are taken from the high angle than the men's, which implies a stance that is submissive in metaphoric sense. According to Kress and van Leeuwen $(1996,2006)$, if a represented participant is seen from a high angle, then the relation is depicted as one in which the viewer has power over the represented participant in the image. On the whole, level angle is the most common vertical angle deployed in the data. If the represented advertiser is at eye level, the point of view is one of equality and there is no power difference between the viewer and the participant in the image. Given the luring nature of the genre, the level angle then appears to be the most ideal vertical angle to be deployed in personal ad images.

\section{Conclusion}

The goals of this paper were twofold. The first was to identify and describe dominant patterns of pose features that are mobilized by the men and women in their images. The purpose was to determine common represented attitude through the advertisers' body language and the resources they use to affiliate with viewers. The clusters of resources and represented attitudes are related to the behaviour in the 'attraction' phase of a courtship 
initiation ritual to determine if face-to-face behaviours are replicated in the advertisers' poses. The findings presented thus far show that the cluster of an up-curved mouth shape, a direct gaze and a close shot are the most frequently tendered resources by the men and women, therefore bearing the most mate-ability value in the corpus. The advertisers appear to orient to what is expected in the context of courtship initiation in this particular genre, and are able to produce socially specific visual practices that are comparable to the attraction phase in a face-to-face courting ritual. Their poses are adopted for the purpose of attracting and engaging with others, because as the advertisers deploy the realisation resources of the attraction phase in the images, what they are also doing is instantiating specific attitudes (i.e. affiliative and dominant) and performing a friendly or suggestive persona through which they affiliate with others on my.match.com.

\section{Acknowledgments}

This study was funded by the National University of Malaysia Research Grant (GGPM-10-2013).

\section{References}

Argyle, M. (1988). Bodily communication (2nd ed.). New York, NY, US: Methuen.

Baker, P. (2006). Using corpora in discourse analysis: Continuum. London.

Bartholome, A., Richard, T., \& Alex, B. (2000). "I Want a Man": Patterns of Attraction in All-Male Personal Ads. Journal of Men's Studies, 8(3), 309-321. http://dx.doi.org/10.3149/jms.0803.309

Bolig, R., Stein, P. J., \& McKenry, P. C. (1984). The Self-Advertisement Approach to Dating: Male-Female Differences. Family Relations, 33, 587-592. http://dx.doi.org/10.2307/583839

Brym, R. J., \& Lenton, R. L. (2001). Love Online: A Report on Digital Dating in Canada. Retrieved July 2, 2003, from http://www.nelson.com/nelson/harcourt/sociology/newsociety3e/loveonline.pdf

Cameron, C., Oskamp, S., \& Sparks, W. (1977). Courtship American style: Newspaper ads. The Family Coordinator, 26, 27-30. http://dx.doi.org/10.2307/581857

Costa, M., \& Bitti, P. (2000). Face-ism effect and head canting in one's own and others' photographs. European Psychologist, 5(4), 293-301. http://dx.doi.org/10.1027//1016-9040.5.4.293

De Weerth, C., \& Kalma, A. (1995). Gender differences in awareness of courtship initiation tactics. Sex Roles, 32, 717-734. http://dx.doi.org/10.1007/BF01560186

Department of Statistics Malaysia 2001 at http://www.statistics.gov.my/eng/

Ekman, P. (1993). Facial Expression and Emotion. American Psychologist, 48, 4-384. http://dx.doi.org/10.1037/ 0003-066X.48.4.384

Ekman, P., \& Friesen, W. (1969). The repertoire of nonverbal behavior: categories, origins, usage and coding. Semiotica, 11, 49-98. http://dx.doi.org/10.1515/semi.1969.1.1.49

Ekman, P., Friesen, W. V., O’Sullivan, M., \& Scherer, K. (1980). Relative importance of face, body and speech in judgements of personality and affect. Journal of Personality and Social Psychology, 38, 270-7. ttp://dx.doi.org/10.1037/0022-3514.38.2.270

Fiore, A., \& Donath, J. (2002). Online Personals: An Overview. Retrieved from http://smg.media.mit.edu/papers/ atf/chi2004_personals_short.pdf

Gallant, S., Loriann, W., Fisher, M., \& Cox, A. (2011). Mating Strategies and Self -Presentation in Online Personal Advertisement Photography. Journal of Social, Evolutionary, and Cultural Psychology, 5(1), 106-121. http://dx.doi.org/10.1037/h0099272

Gibbs, J. L., Ellison, N. B., \& Heino, R. D. (2006). Self-presentation in online personals: The role of anticipated future interaction, self-disclosure, and perceived success in Internet dating. Communication Research, 33(2), 1-26. http://dx.doi.org/10.1177/0093650205285368

Givens, D. (1978). The nonverbal basis of attraction: Flirtation, courtship, and seduction. Psychiatry, 41, 346-359.

Givens, D. (2008). The Nonverbal dictionary of gestures, signs \& body language cues. Washington: Center for Nonverbal Studies Press.

Goffman, E. (1959). The Presentation of Self in Everyday Life. New York: Doubleday.

Goffman, E. (1979). Gender Advertisement. Harvard University Press.

Guerrero, L. K., \& Floyd, K. (2006). Nonverbal communication in close relationships. Mahwah, NJ: Lawrence 
Erlbaum Associates.

Hall, E. T. (1966). The Hidden Dimension. Garden City, N.Y.: Doubleday.

Hall, J., \& Friedman, G. (1999). Status, Gender, and Nonverbal Behavior: A Study of Structured Interactions between Employees of a Company. Personality and Social Psychology Bulletin, 25, 1082-1091. http://dx.doi.org/10.1177/01461672992512002

Halliday, M. A. K. (1996). On grammar and grammatics. In R. Hasan, C. Cloran, \& D. G. Butt (Eds.), Functional descriptions: Theory in practice (pp. 1-38). Amsterdam \& Philadelphia: John Benjamins. http://dx.doi.org/10.1075/cilt.121.03hal

Halliday, M. A. K., \& Matthiessen, C. M. I. M. (2004). Introduction to Functional Grammar (3rd ed.). London: Edward Arnold.

Henningsen, D. D. (2004). Flirting with meaning: An examination of miscommunication in flirting interactions. Sex Roles, 50, 481-489. http://dx.doi.org/10.1023/B:SERS.0000023068.49352.4b

Hogben, S., \& Coupland, J. (2000). Egg seeks sperm. End of story?: Articulating gay parenting in small ads for reproductive partners. Discourse and Society, 11(4). 459-486. http://dx.doi.org/10.1177/0957926500011 004002

Hood, S. (2011). Body language in face-to-face teaching: A focus on textual and interpersonal meaning. In S. Dreyfus, S. Hood, \& M. Stenglin (Eds.), Semiotic margins: meaning in multimodality. London. Continuum.

Hunston, S. (2002). Corpora in applied linguistics. Cambridge: Cambridge University Press. http://dx.doi.org/10.1017/CBO9781139524773

Jones, R. (2009). Technology and Sites of Display. In C. Jewitt (Ed.), The Routledge Handbook of Multimodal Analysis (pp. 114-126). Oxon: Routledge.

Kendon, A. (1981). Introduction: Current issues in the study of non-verbal communication. In Nonverbal Communication Interaction and Gesture. The Hague: Mouton. http://dx.doi.org/10.1515/9783110880021.1

Klement, J. A. (1997). Love at First Byte: Internet Romance is Cheaper, Less Stressful Than a Blind Date. The Salt Lake Tribune.

Knapp, M. L., Wiemann, J. M., \& Daly, J. A. (1978). Nonverbal communication: Issues and appraisal. Human Communication Research, 4, 271-279. http://dx.doi.org/10.1111/j.1468-2958.1978.tb00616.x

Kress, G., \& Van Leeuwen, T. (1996). Reading Images - The Grammar of Visual Design. London: Routledge.

Kress, G., \& van Leeuwen, T. (2006). Reading images: The grammar of visual design (2nd ed.). London: Routledge.

Marley, C. (2000). Beyond the usual: The modification of gender in a British dating ads column. Text-Interdisciplinary Journal for the Study of Discourse, 20(3), 271-306. http://dx.doi.org/10.1515/text. 1.2000.20.3.271

Martinec, R. (2001). Interpersonal resources in action. Semiotica, 135, 1(4), 117-145. http://dx.doi.org/10. 1515/semi.2001.056

Martinec, R. (2004). Gestures that co-occur with speech as a systematic resource: the realization of experiential meaning in indexes. Social semiotics, 14(2), 193-213. http://dx.doi.org/10.1080/1035033042000238259

Martinec, R. (2005). Topics in multimodality. In R. Hasan, C. M. I. M. Matthiessen, \& J. Webster (Eds.), Continuing discourse on language (Vol. 1, pp. 157-181). London: Equinox.

Mehrabian, A. (1971). Silent Messages (1st ed.). Wadsworth. Belmont.

Mehrabian, A. (1981). Silent Messages: Implicit Communication of Emotions and Attitudes (2nd ed.). Wadsworth. Belmont.

Mehu, M., Little, A. C., \& Dunbar, R. I. M. (2008). Sex differences in the effect of smiling on social judgment: An evolutionary approach. Journal of Social, Evolutionary, and Cultural Psychology, 2(3), 103-121. http://dx.doi.org/10.1037/h0099351

Messinger, D., Fogel, A., \& Dickson, K. L. (2001). All smiles are positive, but some smiles are more positive than others. Developmental Psychology, 37, 642-653. http://dx.doi.org/10.1037/0012-1649.37.5.642

Miller, E., Smith, J., \& Trembath, D. (2000). The 'skinny' on body size requests in personal ads. Sex Roles, 43, 129-141. http://dx.doi.org/10.1023/A:1007047914166 
O'Donnell, M. (2008). UAM Corpus Tool. Madrid.

Okami, P., \& Shackelford, T. K. (2001). Human sex differences in sexual psychology and behavior. Annual Review of Sex Research, 12, 186-241.

Otta, E., Lira, B. B. P., Delevati, N. M., Cesar, O. P., \& Pires, C. S. G. (1994). The effect of smiling and of head tilting on person perception. The Journal of Social Psychology, 128, 323-331. http://dx.doi.org/10.1080/00 223980.1994 .9712736

Painter, C., \& Martin, J. (2010). Intermodal complementarity: Modelling affordances across image and verbiage in children's picture books. Ilha do Desterro: A Journal of English Language, Literatures in English and Cultural Studies.

Rogers, J. (1999). Flirting fascination. Psychology Today, 32(1), 36-41, 64-70.

Shalom, C. (1997). That great supermarket of desire: attributes of the desired other in personal advertisements. In K. Harvey, \& C. Shalom (Eds.), Language and Desire: encoding sex, romance and intimacy. London: Routledge.

Tian, P. (2010). Multimodal Evaluation: Sense and Sensibility in Anthony Browne's Picture Books. Unpublished thesis. University of Sydney.

Van Leeuwen, T. J., \& Jewitt, C. (2000). Handbook of Visual Analysis. London: Sage.

Walther, J. B., \& Parks, M. R. (2002). Cues filtered out, cues filtered in: Computer-mediated communication and relationships. In M. L. Knapp, \& J. A. Daly (Eds.), Handbook of Interpersonal Communication (3rd ed), (pp. 529-563). Thousand Oaks, CA: Sage.

Whitty, M. T. (2003). Cyber-flirting: Playing at love on the internet. Theory and Psychology, 13, 339-357. http://dx.doi.org/10.1177/0959354303013003003

Zappavigna, M., Dwyer, P. \& Martin, J. R. (2008). Just like sort of guilty kind of: The rhetoric of tempered admission in Youth Justice Conferencing. In M. Zappavigna (Ed.), ASFLA 2007 Proceedings. Australian Systemic Functional Linguistics Association. Retrieved from http://www.asfla.org.au/2008/07/31/therhetoric-of-tempered-admission-in-youth-justice-conferencing/

\section{Note}

Note 1. The age range of the advertisers is based on statistics of marriage trend in Malaysia for the year 2000. A national survey revealed that Malaysian male adults' age at marriage is 28.6 years, while for females, it is 25.1 years. At marriage, there is an average of four to five years' difference in the age of the husband and wife (Department of Statistics Malaysia 2001). Similar pattern are observed across ethnic lines, with the mean age at first marriage for men highest for Chinese (30.6 years), followed by Indians (28.8 years) and Malays (27.8 years). This pattern of age at first marriage among the ethnic groups was similarly observed for women whereby the highest was recorded for the Chinese ( 27.0 years), followed by the Indians (25.4 years) and Malays (24.5 years). However, the purpose of this research does not delimit the status of the advertiser to only those who have never been married, but also include divorcees, widows and widowers and those who are separated. Given the above statistics, it would be reasonable to take the average marrying age for both men and women and extend 5 years on each side to include the age variation.

\section{Copyrights}

Copyright for this article is retained by the author(s), with first publication rights granted to the journal.

This is an open-access article distributed under the terms and conditions of the Creative Commons Attribution license (http://creativecommons.org/licenses/by/3.0/) 